\title{
GEOMAGNETIC DISTURBANCES AT F1-LAYER HEIGHTS UNDER DIFFERENT SOLAR ACTIVITY CONDITIONS OVER NORILSK
}

\author{
G.P. Kushnarenko \\ Institute of Solar-Terrestrial Physics SB RAS, \\ Irkutsk, Russia,kusch@iszf.irk.ru
}

O.E. Yakovleva

Institute of Solar-Terrestrial Physics SB RAS,

Irkutsk, Russia, yakovleva@isz.j.irk.ru

\author{
G.M. Kuznetsova \\ Institute of Solar-Terrestrial Physics SB RAS, \\ Irkutsk,Russia,kuz@iszf.irk.ru
}

\begin{abstract}
We analyze the influence of geomagnetic disturbances on the electron density $N_{\mathrm{e}}$ at Norilsk ionospheric station $\left(69^{\circ} \mathrm{N} ; 88^{\circ} \mathrm{E}\right)$ at F1-layer heights (120$200 \mathrm{~km}$ ). For the analysis, we have selected 25 moderate and weak geomagnetic disturbances for two seasons spring and fall - of 2003-2014. Using the $N_{\mathrm{e}}$ values obtained from measurements made with the Norilsk digisonde during this period, we analyze $N_{\mathrm{e}}$ variations during geomagnetic disturbances in spring and fall for a long period of time. We determine the effect of springfall asymmetry occurring in all solar activity phases and
\end{abstract}

manifesting itself in a significant decrease in the electron density during the main phase of fall storms at all heights in comparison with quiet days: up to 2.6 times at a height of $200 \mathrm{~km}$ and slightly less at lower heights. This phenomenon is not observed during spring disturbances: $\mathrm{Ne}$ variations are much weaker.

Keywords: geomagnetic disturbances, electron density, spring-fall asymmetry.

\section{INTRODUCTION}

The main cause of electron density variations during geomagnetic disturbances is known to be a change in the neutral composition of the thermosphere. Each ionospheric region has its unique structural features and different neutral composition and therefore responds to disturbances generated by geomagnetic storms on its own way.

Effects of geomagnetic storms at F1-layer heights have little been studied until recently. As derived from [Kushnarenko et al., 2012, 2013; Buresova, Lastoviska, 2001; Buresova et al., 2002; Mikhailov, 2008], manifestations of the disturbances in the lower part of the $F$ layer are complex and ambiguous, and responses to geomagnetic disturbances at heights $120-200 \mathrm{~km}$ are much less studied than those in the F2 layer. During low solar activity, effects of the disturbances have been found to manifest themselves only slightly at a height below $170 \mathrm{~km}$. Regular measurements with digital ionosondes at the ionospheric stations Irkutsk and Norilsk and accumulation of electron density data provided the opportunity to examine the effects of geomagnetic disturbances on $N_{\mathrm{e}}$ at F1-layer heights (120-200 km) under different solar activity conditions in 2003-2014.

Kushnarenko et al. [2018] have analyzed $N_{\mathrm{e}}$ variations during geomagnetic disturbances at F1-layer heights in 2003-2014, using data from the digital ionospheric station Irkutsk $\left(52^{\circ} \mathrm{N}, 104^{\circ} \mathrm{F}\right)$. They have found the spring-fall asymmetry of geomagnetic storm effects at these heights.

In this paper, we continue studying the ionization response at these heights to geomagnetic storms at the high-latitude station Norilsk under different solar activity conditions in 2003-2014.

\section{DATA}

We have examined the electron density response at F1-layer heights $(120-200 \mathrm{~km})$ in the vicinity of Norilsk to geomagnetic disturbances during two seasons spring and fall. To do this, we have used the $N_{\mathrm{e}}$ values obtained from measurements made with a digisonde $\left(69^{\circ} \mathrm{N}, 88^{\circ} \mathrm{E}\right)$ at Norilsk station in 2003-2014. We have identified and analyzed 25 moderate and weak geomagnetic storms of the period under study. Characteristics of these disturbances are given in Table 1. From all the studied disturbances ( 25 events) as a vivid example we have chosen storms for three periods corresponding to different solar activity phases (Table 2): decrease (2003), minimum (2008), and maximum (2014).

When processing the $N_{\mathrm{e}}$ data array, we came up against numerous gaps and lack of data even for weak geomagnetic disturbances. The impact of severe storms on ionization at F1-layer heights is very difficult to trace because there are no data for these heights owing to absorption effects in the lower ionospheric layers.

\section{SPRING-FALL ASYMMETRY OF GEOMAGNETIC DISTURBANCES}

Figure 1 shows $N_{\mathrm{e}}$ variations for Norilsk station in spring for the three selected periods corresponding to different solar activity phases: decrease (2003), minimum (2008), and maximum (2014). On the left are $N_{\mathrm{e}}$ variations at $150,180,190$, and $200 \mathrm{~km}$ during the maximum development of three spring storms; on the right are $N_{\mathrm{e}}$ variations at the same heights on quiet days corresponding to each storm.

At F1-layer heights there are no marked effects of spring geomagnetic storms on electron density. Note that at $12 \mathrm{LT} N_{\mathrm{e}}$ decreased on average 1.6 times at 190 
Table 1

Geomagnetic disturbances under study

\begin{tabular}{|c|c|c|c|}
\hline Quiet days & Day of the storm onset & Indices $\left(A_{\mathrm{p}}, D s t\right)$ & Storm maximum (date and UT) \\
\hline October $10-12,2003$ & October 14,2003 & $A_{\mathrm{p}}=66, D s t=-85$ & October 14 at 23:00 \\
\hline April 18-20, 2003 & April 30, 2003 & $A_{\mathrm{p}}=45, D s t=-67$ & April 30 at 03:00 \\
\hline May 04, 2003 & April 23, 2003 & $A_{\mathrm{p}}=27, D s t=-39$ & April 23 at $06: 00$ \\
\hline March 06-08, 2004 & March 10, 2004 & $A_{\mathrm{p}}=94, D s t=-105$ & March 10 at 08:00 \\
\hline September 12, 2004 & September 14, 2004 & $A_{\mathrm{p}}=56, D s t=-50$ & September 14 at 19:00 \\
\hline April 28, 2005 & May 01,2005 & $A_{\mathrm{p}}=39, D s t=-47$ & May 01 at 04:00 \\
\hline April 02, 2005 & April 04, 2005 & $A_{\mathrm{p}}=80, D s t=-55$ & April 04 at 23:00 \\
\hline August 30, 2005 & September 01, 2005 & $A_{\mathrm{p}}=67, D s t=-80$ & September 01 at 24:00 \\
\hline April 12, 2006 & April 14, .2006 & $A_{\mathrm{p}}=80, D s t=-111$ & April 14 at 10:00 \\
\hline March 05, 2006 & March 10, 2006 & $A_{\mathrm{p}}=39, D s t=-37$ & March 10 at 23:00 \\
\hline October 12,2006 & October 13,2006 & $A_{\mathrm{p}}=56, D s t=-49$ & October 13 at 23:00 \\
\hline March 06, 2008 & March 09, 2008 & $A_{\mathrm{p}}=67, D s t=-72$ & March 09 at 05:00 \\
\hline October 26,2008 & October 29,2008 & $A_{\mathrm{p}}=32, D s t=-24$ & October 29 at 08:00 \\
\hline April 10, 2010 & April 06, 2010 & $A_{\mathrm{p}}=56, D s t=-59$ & April 06 at 11:00 \\
\hline October 01,2010 & September 24, 2010 & $A_{\mathrm{p}}=27, D s t=-30$ & September 24 at 17:00 \\
\hline October 29,2010 & October 23,2010 & $A_{\mathrm{p}}=48, D s t=-35$ & October 23 at 14:00 \\
\hline October 01,2010 & September 24, 2010 & $A_{\mathrm{p}}=27, D s t=-26$ & September 24 at 17:00 \\
\hline April 04, 2012 & April 05, 2012 & $A_{\mathrm{p}}=27, D s t=-54$ & April 05 at 10:00 \\
\hline September 10, 2012 & September 04, 2012 & $A_{\mathrm{p}}=32, D s t=-63$ & September 04 at 08:00 \\
\hline September 15, 2013 & September 13, 2013 & $A_{\mathrm{p}}=22, D s t=-7$ & September 13 at 17:00 \\
\hline September 29, 013 & September 24, 2013 & $A_{\mathrm{p}}=32, D s t=-24$ & September 24 at 14:00 \\
\hline March 06, 2013 & March 02, 2013 & $A_{\mathrm{p}}=27, D s t=-16$ & March 02 at 02:00 \\
\hline April 18, 2014 & April 20, 2014 & $A_{\mathrm{p}}=48, D s t=-28$ & April 20 at 14:00 \\
\hline March 11, 2014 & March 13, 2014 & $A_{\mathrm{p}}=27, D s t=-29$ & March 13 at $02: 00$ \\
\hline August 26, 2014 & August 29, 2014 & $A_{\mathrm{p}}=27, D s t=-33$ & August 29 at 11:00 \\
\hline
\end{tabular}

The $A_{\mathrm{p}}, F 10.7$, and $D s t$ indices were taken from the WDC-C2 database in Kyoto [http://wdc.kugi.kyoto-u.ac.jp].

Annual average $F 10.7$ in 2003-2014

\begin{tabular}{|l|c|c|c|c|c|c|c|c|c|c|c|c|}
\hline Year & 2003 & 2004 & 2005 & 2006 & 2007 & 2008 & 2009 & 2010 & 2011 & 2012 & 2013 & 2014 \\
\hline$F 10.7$ & 128 & 106 & 98 & 80 & 74 & 69 & 71 & 80 & 113 & 120 & 123 & 146 \\
\hline
\end{tabular}

and $200 \mathrm{~km}$ for all the three storms and changed 1.1-1.4 times at lower F1-layer heights $(150 \mathrm{~km})$. Such $N_{\mathrm{e}}$ behavior is observed in almost all spring storms considered.

$N_{\mathrm{e}}$ variations during fall geomagnetic disturbances differ significantly from spring ones. The electron density decreases considerably at all heights during storm main phase (Figure 2). The fall effect involves a decrease in $N_{\mathrm{e}} 2-2.6$ times at $200 \mathrm{~km}$ and a marked decrease - 1.4-1.8 and 1.5 times - at 180 and $150 \mathrm{~km}$ respectively. Such variations are typical for almost all fall storms.

The observed spring-fall asymmetry of geomagnetic storms may be connected with seasonal variations in the height of the region in which atomic ions predominate over molecular ions [Buresova, Lastovicka, 2001]. This leads to a change in the height of the F1-layer maximum. During the disturbances, the electron density at F1-layer heights is affected by changes in the neutral atmosphere composition and ionization rate as well as photochemical processes.

The effect of photochemical processes when F1 layer is lowering becomes predominant in denser atmospheric layers due to shorter lifetime of free electrons.

Another possible cause of the observed asymmetry is deeper penetration of the disturbances from auroral regions into lower latitudes in fall seasons. In the disturbed region, as derived from satellite measurements [Goncharenko et al., 2006], the proportion of the neutral component of the thermosphere rises, which entails a change in the ionic composition at F1-layer heights and a decrease in the electron density at the heights considered.

\section{CONCLUSIONS}

Near Norilsk, the effects of geomagnetic storms on the electron density exhibit spring-fall asymmetry at F1-layer heights, which manifests itself in all solar activity periods of 2003-2014.

During fall geomagnetic disturbances, the electron density decreases markedly (to 2.6 times) at 190 and $200 \mathrm{~km}$; the effect is weaker at lower heights. On the contrary, spring storms feature a slight decrease in $N_{\mathrm{e}}$ at 

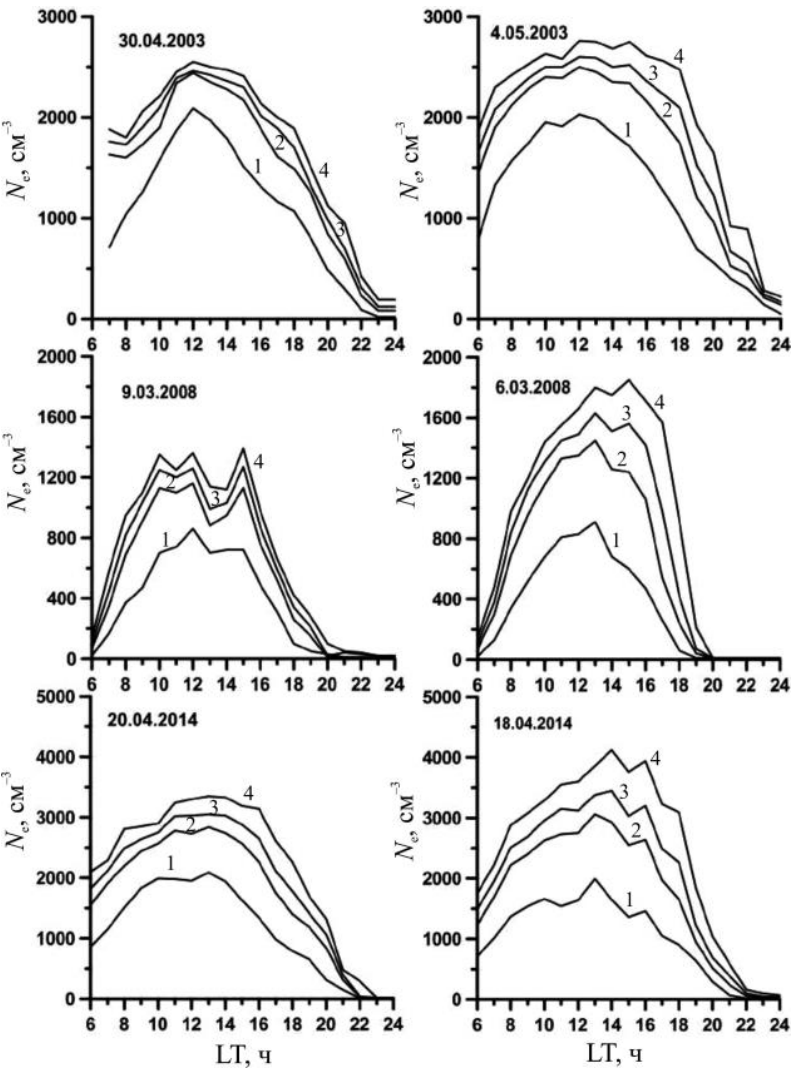

Figure 1. $N_{\mathrm{e}}$ behavior during the maximum development of three spring storms (left panel) and on quiet days corresponding to these storms (right panel) at $150 \mathrm{~km}(1), 180 \mathrm{~km}$ (2), $190 \mathrm{~km} \mathrm{(3),} 200 \mathrm{~km}(4)$
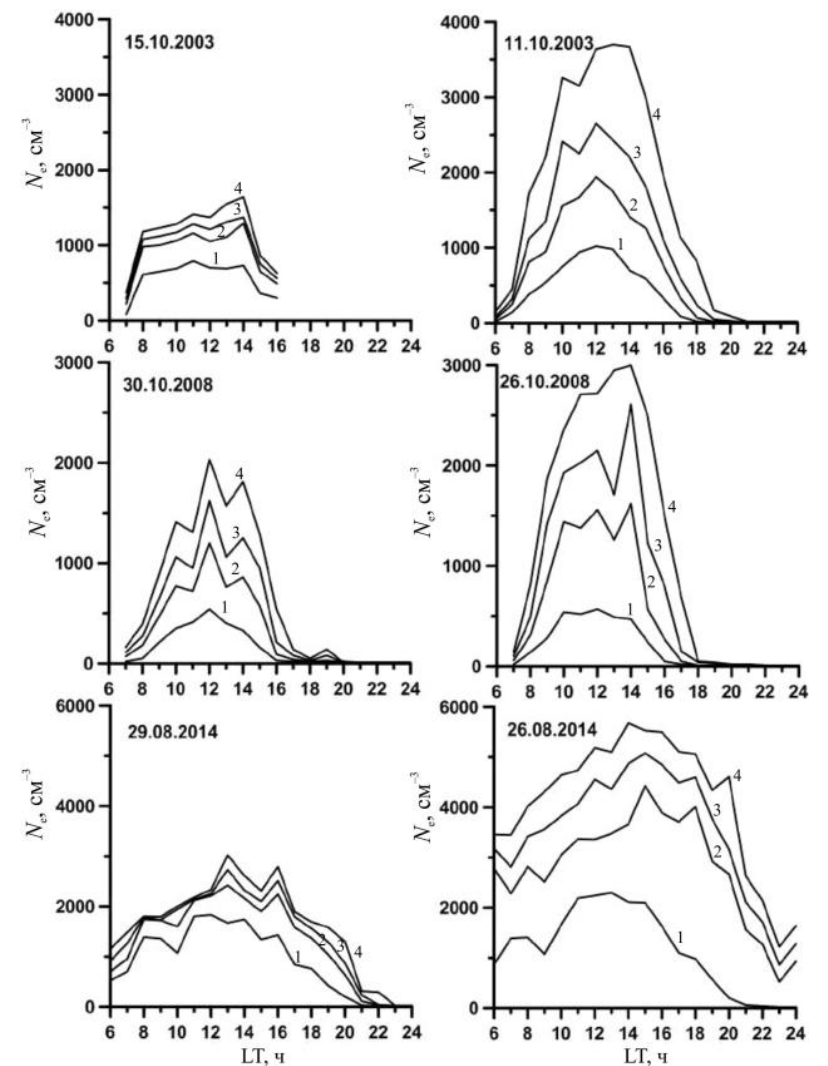

Figure 2. The same as in Figure 1 for the fall period: 150 km (1), 180 km (2), 190 km (3), 200 km (4)
150-200 $\mathrm{km}$ in comparison with quiet conditions.

The electron density in all the periods of disturbances considered always decreases at the F1-layer heights.

The work was performed with budgetary funding of Basic Research program II.16.1.1. «Research into the influence of solar activity and processes in the lower atmosphere on thermodynamic characteristics of the atmosphere, World Ocean, and climate». The results were obtained using the equipment of Center for Common Use «Angara» [http://ckp-rf.ru/ckp/3056].

\section{REFERENCES}

Buresova D., Lastovicka J. Changes in the F1 region electron density during geomagnetic storms at low solar activity. J. Atmos. Solar-Terr. Phys. 2001, vol. 63, iss. 5, pp. 537-544. DOI: 10.1016/S1364-6826(00)00167-X.

Buresova D., Lastovicka J., Altadill D., Miro G. Daytime electron density at the F1-region in Europe during geomagnetic storms. Ann. Geophys. 2002, vol. 20, pp. 1007-1021. DOI: 10.5194/angeo-20-1007-2002.

Goncharenko L., Salah J., Crowley G., Paxton L.J., Zhang Y., Coster A., Rideout W., Huang C., Zhang S., Reinisch B., Taran V Large variations in the thermosphere and ionosphere during mino geomagnetic disturbances in April 2002 and their association with IMF $\mathrm{B}_{\mathrm{y}}$. J. Geophys. Res. 2006, vol. 111, A03303. DOI: 10.1029/2004JA010683.

Kushnarenko G.P., Kuznetsova G.M., Ratovsky K.G., Kolpakova O.E. Some ionospheric parameters response on geomagnetic disturbances at the heights lower layer F1 maximum during September and April 2005. Geomagnetizm i aeronomiya [Geomagnetism and Aeronomy]. 2012, vol. 52, no. 3, pp. 378-385. (In Russian).

Kushnarenko G.P., Kuznetsova G.M., Polekh N.M., Ratovsky K.G. The geomagnetic storms effects at ionospheric layer F1 heights in Irkutsk during decrease and minimum of solar activity. Solnechno-zemnaya fizika [Solar-Terrestrial Physics]. 2013, no. 22, pp. 31-34. (In Russian).

Kushnarenko G.P., Kuznetsova G.M., Yakovleva O.E. The geomagnetic storms effects at ionospheric layer F1 heights during the different periods of solar activity (st. Irkutsk). Geomagnetizm $i$ aeronomiya [Geomagnetism and Aeronomy]. 2018, vol. 58, no. 2, pp. 211-216. (In Russian). DOI: $10.7868 /$ S0016794018020062.

Mikhailov A.V. Ionospheric F1 layer long-term trends and the geomagnetic control concept. Ann. Geophys. 2008, vol. 26, pp. 3793-3803. DOI: 10.5194/angeo-26-3793-2008.

URL: http://wdc.kugi.kyoto-u.ac.jp (accessed October 1, 2018). 2018)

URL: http//ckp-rf.ru/ckp/3056 (accessed October 1,

How to cite this article

Kushnarenko G.P., Yakovleva O.E., Kuznetsova G.M. Geomagnetic disturbances at F1-layer heights under different solar activity conditions over Norilsk. Solar-Terrestrial Physics. 2019. Vol. 5. Iss. 2. P. 113-115. DOI: 10.12737/stp-52201916. 